\title{
A Contribuição do Festival É Tudo Verdade ao Cânone do Documentário Brasileiro
}

\author{
Juliana Muylaert Mager \\ Laboratório de História Oral e Imagem, Universidade Federal Fluminense, Niterói \\ jumuylaert@gmail.com \\ https://orcid.org/0000-0003-4199-2969
}

RESUMO O presente artigo integra um conjunto de pesquisas que têm repensado o lugar dos festivais na cultura cinematográfica. Nossa análise se volta para o É Tudo Verdade Festival Internacional de Documentários, propondo um debate sobre o cânone cinematográfico mobilizado pelo evento. Dirigimos especial atenção às mostras retrospectivas do documentário brasileiro e às publicações apoiadas pelo festival. Buscamos, ainda, colocar as propostas do evento em diálogo com outras leituras do cânone elaboradas por festivais brasileiros de filme documentário. Esperamos, assim, oferecer uma contribuição inicial para um debate sobre os festivais audiovisuais e a história do cinema brasileiro.

PALAVRAS-CHAVE Festivais de cinema; documentário; cânone; cinema brasileiro; É Tudo Verdade - Festival Internacional de Documentários.

\section{Introdução: Documentário brasileiro e festivais de cinema}

Nos anos 1970 e 1980, a publicação de importantes trabalhos de Paulo Emílio Salles Gomes (1980), Maria Rita Galvão (1975) e Jean-Claude Bernardet (1979) sobre os primeiros momentos da atividade cinematográfica do país sinalizava um movimento de valorização dos "filmes de cavação" na história do cinema brasileiro. ${ }^{1}$ No entanto, como aponta Schvarzman (2007), a perspectiva desses autores ainda representava uma exceção entre as pesquisas de historiografia do cinema. Em 1995, Jean-Claude Bernardet (2008) voltou a ressaltar, como problemas da historiografia do cinema brasileiro, o olhar voltado para a produção cinematográfica e a preferência pelo longa-metragem, deixando de lado o

\footnotetext{
1 "Cavação" foi o termo empregado para definir (de forma negativa) os filmes naturais produzidos nas primeiras décadas do cinema brasileira, incluindo obras de encomenda e propaganda (Ramos e Miranda 2000, 220).
} 
documentário de curta ou média metragem, historicamente sustentáculo da produção brasileira.

Somente nos anos 2000, a temática do documentário ganharia maior espaço na academia e no mercado editorial, incluindo também trabalhos de cunho historiográfico. No início da década, Francisco Teixeira (2003) organiza o que pode ser considerado um dos primeiros livros com a proposta de "sistematizar a história do documentário brasileiro" (Schvarzman 2007, 27). Com o subtítulo "tradição e transformação", esta obra trouxe textos de doze autores, a maior parte deles ligados à pesquisa acadêmica, mas também com inserção profissional na atividade cinematográfica. Com duas partes, o livro combinava ensaios de perfil temático, voltados para questões que atravessam o campo documental no país e reflexões monográficas, dedicadas a obras de autores específicos de diferentes tempos particularmente do cinema moderno.

Além dessa coletânea, gostaríamos de destacar outras publicações do mesmo período. Em perfil autoral, a obra de Consuelo Lins (2004), professora da UFRJ, pesquisadora e cineasta, sobre Eduardo Coutinho, valorizando seu trabalho como documentarista, e o livro de Sheila Schvarzman (2004) sobre Humberto Mauro, publicado a partir de sua tese de doutorado. Sobre os processos de institucionalização do cinema pelo Estado no século XX, o livro de José Inácio Souza (2003), que discute entre outras mídias, os cinejornais. Em proposta panorâmica e sintética sobre a história do documentário, destacamos a obra de Labaki (2006), fundador e principal programador do $E ́$ Tudo Verdade, que estudaremos mais atentamente na próxima secção do artigo, e o livro de Sílvio Da-Rin (2004), publicado a partir da dissertação do autor, com um percurso histórico em perspectiva mundial. Sobre o documentário contemporâneo, vale mencionar o livro de Cláudia Mesquita e Consuelo Lins (2008), ambas professoras universitárias com trajetória em festivais, que aborda a produção documental desde os anos 1990 a partir de questões e tendências, sem perder de vista a dimensão autoral.

Como ponto comum a essa bibliografia, notamos um certo entusiasmo com o momento de destaque vivido pelo documentário no cenário nacional e mundial. Alguns autores, como Lins e Mesquita (2008), citam diretamente os festivais e, particularmente, o É Tudo Verdade, como agentes desse processo. 0 perfil dos autores, ressalvadas algumas diferenças, aponta para um diálogo entre as universidades e o campo profissional do cinema, incluindo a atuação em festivais, a crítica e a realização de filmes. As pesquisas assumem um olhar para a história do documentário, 
privilegiando as obras a partir do período moderno, sem excluir outros recortes. Os cânones propostos valorizam o documentário autoral, o que talvez ajude a explicar a predominância de obras do cinema moderno e contemporâneo.

Nos anos 2010, nota-se um crescimento de pesquisas que buscam repensar os modelos historiográficos e os conceitos de documentário, a fim de ir além do binômio cinema/autor e da produção, incluindo outras esferas da atividade cinematográfica, tais como a distribuição, a exibição e a recepção. Parte desse processo, notamos na última década o crescimento dos estudos de festivais de filmes, como as teses de doutorado de Bianca Pires (2019), sobre os públicos cinéfilos e festivais, de Tetê Mattos (2016), sobre o Festival do Rio, ou de Izabel Melo (2018), sobre as Jornadas de Cinema da Bahia e o movimento cineclubista. Além desses trabalhos, artigos, ensaios, capítulos e diagnósticos setoriais dedicados aos festivais formam uma bibliografia inicial, porém crescente, dedicada ao tema. Sobre os festivais de documentário e outros eventos especializados merecem menção, entre outros, a tese da autora, com foco no Recine e É Tudo Verdade (Mager 2019), a dissertação de Kamyla Faria Maia (2015), também sobre o É Tudo Verdade, o artigo de Luciana Freitas (2020) sobre eventos voltados para o cinema indígena e a resenha de Beatriz Rodovalho Gonçalves (2020) sobre o CachoeiraDoc 2020.

No presente artigo, propomos um estudo do papel do festival É Tudo Verdade como espaço de articulação entre distribuição, exibição e recepção, para analisar sua contribuição na legitimação ou contestação do cânone documental vigente. Desse modo, a pergunta que orienta o trabalho indaga sobre o impacto dos festivais de filmes na história do audiovisual e tem sido colocada por pesquisadores que se dedicaram ao estudo desses eventos como fenômeno histórico dos séculos XX e XXI. 0 texto se insere, assim, em um conjunto recente de trabalhos que buscam alterar o "papel normalmente subestimado" dos festivais audiovisuais "na escrita da história do cinema" (Stringer 2013, 134). Questionamos o lugar dos festivais de filmes nos processos de inscrição das obras na história, na esteira de autores como Di Chiara e Re (2011), para quem a curadoria dos festivais pode ser influenciada pela atividade de historiadores por meio de sua programação: "um festival de filmes pode criar novos cânones, modificando hierarquias postuladas por historiadores e lançando luz para algumas tendências de pesquisa existentes, em detrimento de outras" (Chiara; Re 2011). Em diálogo com essa proposta, no presente artigo buscamos lançar um olhar para a trajetória do festival brasileiro É Tudo Verdade em seus 
vinte e cinco anos, para analisar o tipo de cânone do documentário brasileiro que defende o festival.

$\mathrm{O}$ artigo encontra-se dividido em duas partes. $\mathrm{Na}$ primeira parte, analisamos as estratégias de negociação do cânone do documentário brasileiro do festival É Tudo Verdade, começando pelo cânone proposto pelo diretor e fundador do festival, Amir Labaki (2006). Em seguida, examinamos alguns princípios gerais da programação do festival e nos dedicamos à análise em profundidade das retrospectivas dedicadas ao documentário brasileiro a partir de 1999. Na segunda parte do artigo, analisamos outros festivais audiovisuais temáticos criados nas últimas duas décadas que oferecem versões alternativas ao cânone proposto pelo É Tudo Verdade, destacando o Fórumdoc.bh, o Recine e o Cachoeira Doc. Concluímos, apontando algumas questões iniciais, mas que consideramos fundamentais para o aprofundamento do debate sobre as repercussões dos festivais na articulação do cânone cinematográfico brasileiro.

\section{A construção do cânone: publicações e retrospectivas do É Tudo Verdade}

No ano de 1996, o É Tudo Verdade - I Festival Internacional de Documentários teve sua primeira edição entre 12 e 21 de abril, no Rio de Janeiro, e de 16 a 21 de abril, em São Paulo, contando com o apoio do CCBBRJ, do SESC-SP e do Centro Cultural São Paulo. O release de imprensa apresentava como proposta do evento preencher uma lacuna identificada no setor dos festivais no país, oferecendo um espaço para o documentário como campo criativo. ${ }^{2}$ Como principal responsável pela concepção e curadoria do evento estava o crítico de cinema Amir Labaki, que já havia sido diretor do Museu da Imagem e do Som em São Paulo, e que viria a ocupar, a partir de 2003, uma posição no conselho do destacado International Documentary Festival of Amsterdam - IDFA. A trajetória de Amir Labaki e as diferentes atividades que assume como crítico, diretor de museu, curador de festival e historiador do cinema - sem contar sua atuação

\footnotetext{
2 Em meados dos anos 1990, o setor de festivais de filmes no Brasil iniciava um momento de recuperação. Além da permanência de eventos das décadas anteriores, como o Festival de Brasília e de Gramado, vale mencionar a criação de festivais específicos, em que se destacam o Festival Internacional de Curtas-Metragens criado em 1990, além do Anima Mundi, de filmes de animação e da Mostra Internacional do Filme Etnográfico, criados em 1993. Embora não fosse especificamente dedicado ao cinema documental, a Mostra do Filme Etnográfico abriu grande espaço para esse regime cinematográfico, em diálogo com a antropologia visual.
} 
como cineasta - merecem nossa atenção, uma vez que esses espaços de atuação representam diferentes esferas de articulação, disputa e validação do cânone cinematográfico.

Ao longo dos anos, o festival tem sido um agente ativo na recuperação e reescritura da história do documentário brasileiro. Como pontam Di Chiara e Re (2011), esse trabalho se realiza por meio de estratégias distintas: (1) publicações; (2) retrospectivas; e (3) eventos (conferências, debates). Nesse estudo, nos voltamos para as duas primeiras.

Chiara e Re (2011) sugerem a análise das publicações de um festival como elemento importante para compreender as formas como um festival atua como produtor de uma história do cinema. O É Tudo Verdade realizou diversas publicações ao longo de sua trajetória, com destaque para os catálogos, mas também para a edição de livros apoiados ou mesmo diretamente publicados pelo evento. Destacamos a coletânea de textos das primeiras edições da Conferência Internacional do Documentário, atividade paralela ao festival iniciada em 2001 (Labaki e Mourão 2005); uma compilação de críticas seleccionadas de Labaki (2001); além do já citado livro de história do documentário de Labaki (2006). Os 15 anos do festival foram celebrados com a publicação das memórias do evento (Labaki 2010). Em 2014, o livro resultante da tese de doutorado de Mariana Tavares (2014) sobre a obra de Helena Solberg, foi lançado durante a retrospectiva em homenagem à diretora. No ano seguinte, o festival lançou mais dois livros, um conjunto de textos sobre o documentário de diversos cineastas de diferentes tempos organizados por Labaki (2015), e uma coletânea de escritos de Vladimir Carvalho (2015).

Dada a amplitude desse material, no presente artigo nos centramos exclusivamente na proposta do cânone desenvolvida por Labaki (2006), articulada à análise das retrospectivas do cinema brasileiro. Elaborada a partir de um curso ministrado no Instituto Moreira Salles, em 2005, a obra introdutória de Labaki (2006) apresenta um exercício de valorização do cinema documental em um recorte temporal abrangente. Esse formato originário de aulas, bem como a perspectiva histórica generalizante e de longo escopo, diferenciam o livro de outras obras publicadas no mesmo período, a exemplo das citadas na introdução deste artigo, que assumem a forma de coletâneas de textos ou obras monográficas. Na introdução ao livro, organizado em nove notas sobre o documentário brasileiro, Labaki $(2006,9)$ busca enfatizar o documentário como a "grande locomotiva de criação" da cinematografia nacional. 0 autor destaca a regularidade da produção documental na história do cinema brasileiro, defendendo como 
argumento de valorização, o fato de que "todo grande cineasta brasileiro realizou documentários” (Labaki 2006, 9).

Apresentando sua obra como um "resumo modesto" incapaz de receber o título de uma "verdadeira história do documentário brasileiro", Labaki aponta cineastas e temas ausentes em seu percurso como Benedito Junqueira Duarte e Alberto Cavalcanti, ou uma filmografia sobre o "Brasil como país-continente" e os cinejornais. Como vimos, esses assuntos e autores foram largamente colocados em segundo plano pela bibliografia sobre o documentário brasileiro dos anos 2000. Algumas exceções incluem estudos de Claudio Valentinetti (Teixeira 2003) e Sílvio Da-Rin (2004) sobre Cavalcanti e o olhar sobre os cinejornais no livro sobre o Estado e as mídias de José Inácio Souza (2003). Ao ressaltar essas "falhas" de sua obra, Labaki acaba por assinalar alguns dos temas que poderiam ter afastado sua obra da perspectiva escolhida para pensar o documentário nacional, o cinema de autor.

Na leitura histórica construída no livro, permanece a busca de grandes nomes, adotando como modelo não mais o longa de ficção, mas o documentário autoral (também em longa-metragem). A gênese não-ficcional do cinema é lembrada, estabelecendo o autor uma relação entre o conceito de documentário e os filmes dos primeiros anos de cinema no Brasil. Para Labaki, uma "evolução que progride lentamente até a incorporação de estratégias do drama vai marcar o aparecimento dos primeiros realizadores com 'pegada' autoral na história do cinema brasileiro" (2006, 20). Essa perspectiva acaba por projetar um cinema de autor no período silencioso, momento no qual, como lembra Eduardo Morettin $(2005,137)$, "esses cineastas mal eram vistos como diretores, quanto mais autores".

Vale notar os pontos de contato das narrativas sobre a história presentes nesta obra e nas mostras retrospectivas do É Tudo Verdade. 0 primeiro elemento em comum é, justamente, a valorização de um cinema autoral. No festival, essa abordagem se traduz na predominância de mostras dedicadas à obra de um mesmo cineasta, mesmo para os períodos anteriores à difusão do conceito de "cinema de autor", como no caso de Benedito Junqueira Duarte, homenageado pelo evento em 2010. Um segundo ponto de contato importante é a relação com o cânone. Nota-se, nos dois casos, a importância de se construir um cânone para o documentário brasileiro, reafirmada na ideia dos "pioneiros" do cinema nacional. Esse panteão de obras e "autores" brasileiros, por sua vez, encontra referência em um cânone mundial, do qual as obras do Brasil estão comumente excluídas. Observa-se, assim, a 
tentativa de valorizar o documentário produzido no país, reivindicando um lugar para essa cinematografia na história mundial/geral do cinema.

Essa postura de valorização do "cinema de autor" não se restringe ao trabalho de Labaki, marcando parte da bibliografia dos anos 2000 dedicada ao documentário. Se, por um lado, o surgimento dessa bibliografia especializada começa a alterar o quadro apontado por Bernardet (2008) sobre a historiografia do cinema brasileiro, é preciso, por outro, salientar a continuidade de leituras voltadas para o longa-metragem com circulação comercial nas salas de cinema, excluindo grande parte da história do documentário produzido no país, como argumentam Schvarzman (2007) e Morettin (2005). Além de conferir "um estatuto de autoria a um trabalho que na época era desprovido deste cunho" (Morettin 2005, 137), essa vertente acaba por contribuir para manter excluída da história do cinema grande parte da produção documental cujos caminhos cruzam outros cinemas: doméstico, amador, experimental, comercial/ institucional.

Além das publicações, a programação também é um elemento importante para refletir sobre a relação dos festivais com a história do cinema. A primeira edição do É Tudo Verdade, em 1996, não contou com mostras competitivas ou prêmios, oferecendo ao público espectador uma seleção com 29 documentários em película, divididas entre: Panorama Internacional, Panorama Brasil, e Retrospectiva Santiago Alvarez. A curadoria foi assumida pelo diretor do evento, com a colaboração do documentarista Francisco César Filho. Tanto a mostra de filmes internacionais como a de obras brasileiras buscavam oferecer um "panorama" da produção documental naquele momento, exibindo filmes finalizados entre 1993 e 1996. A retrospectiva dedicada a Alvarez representava, já nessa edição de estreia, uma preocupação em construir por meio do festival um olhar para o passado. Ao reunir um conjunto de filmes do cineasta cubano, realizados entre 1965 e 1987, a mostra valorizava a trajetória desse diretor, pouco exibido no Brasil, em uma perspectiva histórica.

A partir de 1997, inscrições seriam abertas para mostras competitivas, nas categorias 'internacional' e 'brasileira', dando início a uma nova fase do festival. De 1998 em diante, o formato do evento fica mais claro, com as mostras competitivas internacional e brasileira se fixando na programação - uma separação entre secções distintas de longas e curtas teve lugar, de 2002 em diante, no caso dos filmes nacionais, e depois de 2007, para a competição internacional; na $22^{\text {a }}$ edição do festival, em 2017, a competição ganharia uma nova categoria, com a inclusão de uma mostra 
latino-americana. Atividades paralelas também fazem parte da trajetória do evento, com uma menção especial às conferências internacionais do documentário realizadas a partir de 2001. Espaço de reflexão sobre a história do documentário, as conferências se tornaram parte das atividades do É Tudo Verdade, selando uma parceria com a Universidade de São Paulo, em que se destaca a atuação da pesquisadora Maria Dora Mourão.

Ao longo das edições, a programação do festival foi delineando um padrão que combinou secções permanentes com outras temporárias. Esse processo combinou a construção de uma identidade para o É Tudo Verdade, com uma capacidade de adaptação de seus programas, elemento que certamente contribuiu para a consolidação do evento em lugar de destaque no calendário brasileiro, latino-americano e internacional de festivais documentais (Vallejo 2018).

Várias abordagens da relação desse festival com a história do cinema poderiam ser desenvolvidas, considerando a amplitude de seus programas e variedade de secções e obras exibidas por vinte e quatro edições. No espaço do presente artigo, elegemos as retrospectivas como objeto de análise, mais especificamente as mostras dedicadas ao cinema documental brasileiro incluídas no programa do festival desde 1999. Desse modo, buscaremos entender como se realizou a construção de um discurso sobre a história do cinema, destacando o investimento do festival na valorização do documentário na história do cinema brasileiro.

Presentes na programação do É Tudo Verdade desde a $4^{\underline{a}}$ edição do festival, as mostras retrospectivas do documentário brasileiro trouxeram para a programação uma secção voltada para a história do cinema nacional. Uma primeira observação sobre essa mudança no programa do festival envolve a adoção de uma secção específica para o cinema nacional, também presente na mostra competitiva. A divisão nacional/ internacional remete à própria lógica das redes globais de festivais (De Valck 2007). De fato, mesmo depois que os comitês nacionais perderam espaço na seleção das obras a partir de fins dos anos 1960, o nacionalismo ainda se faz presente nos modos de organizar e classificar cineastas e obras. No caso do É Tudo Verdade, o formato escolhido coloca o cinema documentário brasileiro em lugar de relevo. Foram 22 as edições com retrospectivas brasileiras, conforme tabela a seguir: 


\begin{tabular}{|c|c|}
\hline \multicolumn{2}{|c|}{ Festival É Tudo Verdade, 1999-2020 } \\
\hline Ano & Tema/ Cineasta homenageado \\
\hline 1999 & Walter Salles \\
\hline 2000 & Dez vezes Brasil \\
\hline 2001 & Geraldo Sarno \\
\hline 2002 & Cinema na TV \\
\hline 2003 & Eduardo Escorel \\
\hline 2004 & Ver a música \\
\hline 2005 & Retrospectiva 10! (nacional e internacional) \\
\hline 2006 & Jorge Bodanzky \\
\hline 2007 & Linduarte Noronha \\
\hline 2008 & Documentário experimental brasileiro \\
\hline 2009 & Paulo Saraceni \\
\hline 2010 & Benedito Junqueira Duarte \\
\hline 2011 & Poesia é verdade \\
\hline 2012 & Coutinho: o caminho até o "Cabra" \\
\hline
\end{tabular}




\begin{tabular}{|l|l|}
\hline 2013 & Jango e o caminho para 1964 \\
\hline 2014 & Helena Solberg \\
\hline 2015 & Vladimir Carvalho \\
\hline 2016 & Carlos Nader \\
\hline 2017 & Sergio Muniz \\
\hline 2018 & $\begin{array}{l}\text { Retrospectiva online Itaú Cultural: cineastas mulheres no } \\
\text { festival }\end{array}$ \\
\hline 2019 & Nelson Pereira dos Santos \\
\hline 2020 & Especial 25 anos \\
\hline
\end{tabular}

Tabela 1: Retrospectivas brasileiras apresentadas em É Tudo Verdade - Festival Internacional de Documentários.

No caso brasileiro, não bastava mobilizar um cânone do cinema documentário, mas também atuar na construção do mesmo, reivindicando um espaço para a cinematografia nacional na história mundial desse regime cinematográfico. Para esse fim, as mostras brasileiras se fizeram acompanhar, nos catálogos, de informações sobre os cineastas e/ ou as obras escolhidas e de textos - da autoria de Labaki ou de curadores convidados. Como mencionamos anteriormente, alguns dos livros publicados pelo evento foram mobilizados pelas temáticas das retrospectivas (Tavares 2014; Carvalho 2015).

0 gesto de reunir filmes para as mostras implica um olhar sobre os materiais audiovisuais do passado a fim de selecionar determinadas imagens e sons (sempre em detrimento de outras). Os olhares construídos a partir dessas seleções não são inocentes, uma vez que trazem e produzem sentidos para o documentário. Iniciadas com uma mostra em homenagem a Walter Salles, o formato mais comum ao longo das edições da retrospectiva brasileira foi a exibição de obras de um mesmo cineasta. Do total de 22 retrospectivas, 7 contaram com programas temáticos e nada menos do que 
15 são homenagens a cineastas específicos, reforçando a ideia de um cinema documentário autoral. Outro elemento presente nessas retrospectivas é a ideia de reconhecer grandes nomes do cinema documentário.

Essa perspectiva pode ser observada na mostra realizada como parte da programação do festival de 2000 - 'Dez vezes Brasil' -, que reuniu obras de diferentes diretores, buscando montar um panorama de obras importantes do documentário nacional. A escolha do tema encontrava sua motivação nas comemorações dos 500 anos do "descobrimento" do país pelos portugueses e na virada para o século XXI. A seleção foi feita a partir da votação de especialistas convidados pelo festival. ${ }^{3}$ Cada um deles deveria fornecer uma lista dos dez mais relevantes documentários nacionais. Cruzando os resultados, os dez títulos mais votados foram: Cabra Marcado para Morrer (1984); Di (1977); Ilha das Flores (1989); Jango (1984); Viramundo (1965); Aruanda (1960); Mato Eles? (1983); Imagens do Inconsciente I (1986); Garrincha, Alegria do Povo (1963); e O País de São Saruê (1971). 0 texto de apresentação de Labaki (2000) assim descreve a proposta:

0 documentário é o continente desconhecido do cinema brasileiro. A efeméride dos 500 anos do descobrimento estimulou-nos a arriscar um raro mapeamento. Cerca de 40 especialistas, entre cineastas e críticos, aceitaram nosso convite e apontaram os dez documentários nacionais que mais os marcaram. Os dez títulos mais votados formam a retrospectiva nacional deste ano. São três produções dos anos 60, duas dos 70 e cinco dos 80. A complexidade do conjunto desafia, porém, a simples classificação temporal. Nada menos que cinco dos filmes são assinados por próceres do cinema novo e um é autêntico pioneiro do movimento.

Ao selecionar 10 filmes de impacto na história do documentário brasileiro, a retrospectiva se voltava para o passado para estabelecer marcos, a partir do presente, buscando delimitar esta cinematografia como um objeto histórico. Nesse caso, o festival se coloca como espaço criador e reprodutor desse conjunto de obras de referência.

\footnotetext{
${ }^{3}$ Foram eles: Adhemar Oliveira; Amir Labaki; Carlos Augusto Calil; Augusto Sevá; Carlos Alberto Mattos; Aurélio Michiles; Carlos Adriano; Carlos Roberto de Souza; Carlos Reichenbach; Eduardo Escorel; Fernão Pessoa Ramos; Francisco César Filho; Giba Assis Brasil; Guido Araújo; Helena Solberg; Ismail Xavier; João Moreira Salles; JeanClaude Bernardet; João Batista de Andrade; Lucia Nagib; Luiz Zanin Oricchio; Manfredo Caldas; Maria do Rosário Caetano; Máximo Barro; Octavio Bezerra; Pedro Butcher; Regina Jehá; Ricardo Dias; Roberto Berliner; Roberto Moreira; Sergio Bianchi; Sergio Muniz; Silvio Da-Rin; Silvio Tendler; Tata Amaral; Vladimir Carvalho; Walter Carvalho; Wilson Cunha; e Zita Carvalhosa.
} 
Aruanda (1960) é o filme mais antigo da mostra. Assim, podemos notar como a seleção final da mostra acaba por "apagar" da história do documentário brasileiro toda a produção audiovisual até os anos 1950, reforçando o perfil de um documentário autoral, marcadamente ausente das primeiras décadas do século XX. Também foi excluída da lista final toda a produção dos 1990, enquanto a seleção mais ampla com todos os filmes mencionados pelos convidados incluía obras realizadas entre 1929 e 1999. A escolha dos convidados votantes, entre críticos, estudiosos e profissionais do cinema, merece ser analisada como um elemento da programação que já assinala algumas tendências presentes na lista final de filmes. Parece relevante, portanto, notar a presença de nomes ligados à geração do Cinema Novo ou posteriores a ela entre os convidados. Vale ainda notar a prevalência de homens entre os especialistas. Entre os 40 convidados, apenas 5 mulheres. Coincidência ou não, a seleção final da mostra não contava com nenhum filme dirigido por cineastas mulheres. Nesse sentido, vale observar os sentidos construídos pela seleção para construção de uma memória do cinema documentário, com apagamentos, e também valorização de determinados períodos, obras e formatos.

Os princípios envolvidos na organização da retrospectiva 'Dez vezes Brasil', assim como a lista de filmes resultante, apontam para a valorização de um cinema autoral que se estabeleceu a partir dos anos 1960, momento em que a discussão sobre um cinema nacional independente ganhou força no Brasil, tendo sua melhor expressão na geração do Cinema Novo. ${ }^{4}$ Aruanda (1960) foi considerado um dos marcos inaugurais, ou antecedentes do movimento Cinema Novo no Brasil.

Outros filmes associados a esse movimento viriam a ser programados. $\mathrm{Na}$ edição de 2007, a retrospectiva brasileira seguiu seu formato mais comum, homenageando a obra de Linduarte Noronha, diretor de Aruanda (1960). A mostra reafirmava a forte presença da geração do Cinema Novo na programação das retrospectivas nacionais, que nos anos anteriores já haviam exibido filmes de Geraldo Sarno, Eduardo Escorel e Jean-Claude Bernardet. Em 2009, outro documentário exibido na Bienal de 1961 seria lembrado pelo É Tudo Verdade na mostra Lado B - 50 anos de Arraial do Cabo. 0 filme de Paulo César Saraceni e Mário Carneiro também foi

\footnotetext{
${ }^{4}$ O movimento conhecido como Cinema Novo designa um conjunto de obras e autores dos anos 1960 e 1970 que propuseram uma renovação do cinema brasileiro, defendendo a produção de filmes independentes, autorais e voltados para a realidade brasileira e a cultura popular (Simonard 2006).
} 
considerado um dos marcos iniciais do Cinema Novo - mencionado, junto com Aruanda, em uma mesma crítica de Glauber Rocha para o Suplemento Literário do Jornal do Brasil, nos anos 1960. Assinalando o Cinema Novo como momento de renovação e invenção do cinema nacional, em anos seguintes, o festival renderia homenagens a outros nomes ligados ao movimento, como Eduardo Coutinho, Helena Solberg, Vladimir Carvalho e Nelson Pereira dos Santos.

Outro momento do cinema brasileiro cuja presença se fez notar nas mostras e retrospectivas é a "Retomada", termo pelo qual ficou conhecida a cinematografia produzida a partir de meados dos anos 1990, quando o cinema brasileiro viveu momento de crescimento sustentado por uma legislação com base em incentivos fiscais. ${ }^{5}$ Como em outros momentos da história do cinema brasileiro, na construção da narrativa da "Retomada", o cinema nacional foi associado aos filmes de longa-metragem produzidos para os cinemas, excluindo curtas, documentários, filmes institucionais e outros formatos. A primeira edição do É Tudo Verdade apresentou um conjunto de filmes brasileiros concluídos em 1994 e 1995 no Panorama Brasil. A mostra buscava oferecer ao espectador, ainda em meio à "Retomada", um retrato do documentário brasileiro naquele momento, a partir de 12 obras em película (4 longas e 8 curtas), selecionadas pela equipe do festival. Ao lançar luz para a produção documental do período, a mostra acabava por oferecer um questionamento à própria ideia de retomada, reconhecendo a importância desses "outros cinemas" e a continuidade da produção. A seleção incluiu realizadores como Murilo Salles, Walter Salles, Aloysio Raulino e Helena Solberg.

$\mathrm{Na}$ introdução de seu livro de entrevistas com cineastas da "retomada", Lúcia Nagib (2002) observa uma tentativa de encontro com o Brasil presente nesse cinema, que coincide, no caso de muitos dos diretores, com uma volta ao país, após períodos no exterior, uma espécie de "redescobrimento" do Brasil nas telas e na vida. É o caso de Helena Solberg, com o documentário Carmen Miranda - Bananas is my business (1995), que marcava a volta de Solberg ao Brasil por meio dessa polêmica personagem,

\footnotetext{
5 O termo "retomada" (Nagib 2002) foi criado para designar o crescimento da produção de filmes no país a partir de meados dos anos 1990, proporcionado pela reorganização do setor impulsionada pelo estabelecimento de uma legislação baseada em incentivos fiscais no início da década. A "retomada" se opunha, assim, à crise do final dos anos 1980 e início dos 1990, cujo ápice se deu durante o governo Collor, quando uma política de desmonte do setor da cultura interrompeu as políticas públicas para o audiovisual e encerrou órgãos ligados ao cinema, como a Embrafilme.
} 
a ser "redescoberta" pela cineasta. A exibição no É Tudo Verdade apontava outra (re)descoberta: o Brasil (re)encontrava Helena Solberg que, embora tivesse feito parte da geração do Cinema Novo, mantinha-se praticamente desconhecida em seu próprio país.

Walter Salles, outro cineasta incluído no panorama da primeira edição de 1996 com o curta Socorro Nobre (1995), também realizava seu retorno ao país. Central do Brasil (1998) tornou-se ícone desse período. Salles seria, em 1999, o primeiro homenageado das retrospectivas brasileiras do É Tudo Verdade, com cinco documentários seus a integrar essa mostra. Valorizava-se, assim, a importância do documentário na trajetória de Salles, que então se consagrava como um dos nomes de destaque do cinema nacional naquele momento, na esteira do sucesso de Central do Brasil indicado ao Oscar de Melhor Filme Estrangeiro, em 1999. Também era possível mostrar o papel da geração de Salles no desenvolvimento do documentário brasileiro, durante os anos 1980 e 1990.

Em contraponto aos aspectos levantados sobre o cânone das retrospectivas brasileiras do É Tudo Verdade até o momento, podemos apontar edições nas quais se fazem sentir reivindicações pela inclusão de outros tipos de documentário, como filmes realizados por diretoras, películas das primeiras décadas do cinema brasileiro e obras produzidas para a televisão. A primeira retrospectiva brasileira do É Tudo Verdade, dedicada a um cineasta cuja obra remonta ao período anterior aos anos 1950/60, foi a mostra em homenagem a Benedito Junqueira Duarte, realizada em 2010. 0 motivo para a homenagem era o centenário de nascimento do fotógrafo, cineasta e crítico conhecido como B. J. Duarte (1910-1995). Nas memórias do festival, Labaki $(2010,225)$ ressalta a contribuição de B. J. Duarte para o cinema nacional, mas também o silêncio em torno da obra e trajetória do diretor, que associa à posição crítica do cineasta em relação a nomes, movimentos e setores do cinema brasileiro, como o Cinema Novo. Nesse sentido, o diretor do festival assinala a retrospectiva como um espaço para revisar esse apagamento e "acelerar a redescoberta de sua obra pelas novas gerações" (Labaki 2010, 226).

O festival seguia, assim, um movimento de releitura na mesma linha de trabalho já empregada na parceria entre a Secretaria Municipal da Cultura de São Paulo com a Cinemateca Brasileira, que havia sido responsável pelo restauro de parte da obra do diretor. A mostra do É Tudo Verdade exibiu ao público 7 filmes curtos de B. J. Duarte rodados entre 1930 e 1960. Em suas reflexões sobre o festival, Labaki $(2010,226)$ divide a obra do homenageado em dois períodos, sendo o primeiro constituído de filmes dedicados à 
expansão de São Paulo, produzidos desde meados dos anos 1930, quando o diretor trabalhava para a administração paulista; e o segundo marcado pela especialização do diretor no documentário científico, coincidindo temporalmente com a presença de Humberto Mauro no Instituto Nacional do Cinema Educativo (INCE).

Em 2002, com a retrospectiva Cinema na TV - Globo Shell Especial e Globo Repórter, o festival se voltou para um episódio raro de encontro da televisão com o documentário brasileiro, exibindo uma seleção de material desses programas da Rede Globo de Televisão, que estiveram no ar entre 1971 e 1979. A mostra teve curadoria da historiadora, cineasta, e pesquisadora Beth Formaggini, assinalando a parceria e apoio de outras instituições e profissionais que, como observam Chiara e $\operatorname{Re}$ (2011), comumente colaboram na pesquisa exigida para a construção do programa dos festivais. Nas palavras de Amir Labaki $(2010,100)$, a retrospectiva de 2002 envolveu uma verdadeira "arqueologia do documentário brasileiro" para que os 14 filmes pudessem ganhar as telas depois de anos praticamente inacessíveis ao público. A mostra foi resultado de ampla pesquisa de Formaggini realizada junto ao Centro de Documentação da rede Globo, e outros arquivos, desde meados de 2000.

Como fruto desse trabalho, além dos filmes, foi publicado um estudo no catálogo do evento, acompanhado de depoimentos dos diretores dos filmes selecionados (Formaggini 2002). No texto de apresentação, a curadora fala do risco de um "afastamento da memória", levantando o problema da preservação dos acervos audiovisuais televisivos no país, a partir da história do acervo do Globo Repórter, marcada por perdas e pela divisão do material, então espalhado entre o Cedoc, o MIS-SP e as Cinematecas Brasileira e do MAM-RJ (Fomaggini 2002). A retrospectiva efetuava um retorno ao cinema documentário dos anos 1970, em uma operação de reconhecimento dessa produção, realizada para a televisão, considerando sua importância estética e política. A alteração nos circuitos sociais das imagens com a transferência de documentários, antes exibidos na forma de episódios televisivos, para a sala de cinema dos festivais, permitiu ao público contemplar as obras em bloco pela primeira vez, conforme observado por Labaki $(2010,101)$.

Assinalando um último ponto de alteração do cânone do documentário brasileiro no É Tudo Verdade, a presença/ ausência de homenageadas femininas na programação talvez seja o caso que melhor permite observar essas tensões e disputas. No caso das retrospectivas brasileiras, a primeira homenagem a uma cineasta mulher acontece apenas em 2014, o que nos 
mostra o festival como agente de um discurso histórico no qual as cineastas mulheres estão marcadamente ausentes, como na mostra 'Dez vezes Brasil', ou relegadas a uma posição menor. Ainda que possamos considerar a esmagadora presença masculina no âmbito do cinema profissional, no país, é preciso questionar os sentidos envolvidos na elaboração do cânone. Se a presença das mulheres como diretoras é marcadamente limitada na história, a exclusão dos filmes de diretoras acaba por reforçar esse lugar marginal.

Esse cenário começou a apresentar sinais de mudança mais recentemente. A mostra de 2014 no É Tudo Verdade exibiu 8 filmes dirigidos por Helena Solberg entre 1966 e 2013, além do longa As Aventuras de Helena, versão do programa audiovisual dirigido por Betse de Paula adaptada para o festival. Em paralelo, foi lançado um livro sobre a cineasta (Tavares 2014). Esta foi a primeira retrospectiva dedicada inteiramente à cinematografia da diretora realizada no país, iniciando um movimento de reconhecimento que foi antecedido pela exibição de alguns filmes de Solberg em mostras temáticas de festivais como o Fórumdoc e que se fez seguir de uma série de mostras e debates em anos posteriores, como a presença da diretora entre os entrevistados para o projeto Memória do Documentário Brasileiro do CPDOC/FGV, 6 em 2015, e a realização da 'Retrospectiva Helena Solberg', no Centro Cultural Banco do Brasil, com curadoria da Associação Filmes de Quintal, em 2018.

A mostra do cinema de Helena Solberg, assim como outros movimentos mais recentes do festival indicam um movimento no sentido da inclusão de novos sujeitos no cânone do documentário brasileiro. Vale notar que a edição online de 2020 do festival internacional de documentários brasileiro É Tudo Verdade incluiu em sua programação em plataformas digitais uma mostra com os filmes da série Women Make Film, dirigida por Mark Cousins, e um ciclo homenageando as diretoras no festival. ${ }^{7}$ A retomada do cinema de Solberg se inclui entre processos de rediscussão das histórias e do

\footnotetext{
${ }^{6} \mathrm{O}$ "Projeto Memória do Documentário Brasileiro: histórias de vida" é uma iniciativa do Centro de Pesquisa e Documentação de História Contemporânea do Brasil da Fundação Getúlio Vargas. Os trabalhos contaram com uma equipe de 10 integrantes entre pesquisadores e estagiários coordenados por Adelina Novaes e Cruz, Thaís Blank e Arbel Griner. Foram realizadas entrevistas com 13 documentaristas ligados ao Cinema Novo entre 2012 e 2016, incluindo Helena Solberg, Eduardo Coutinho, Silvio Da-Rin, Vladimir Carvalho e Jean-Claude Bernardet. As transcrições e vídeos podem ser encontrados no site do projeto, disponível em: <http://cpdoc.fgv.br/memoria-documentario/apresentacao>.

${ }^{7}$ Como outros eventos normalmente realizados no primeiro semestre, o É Tudo Verdade se viu na necessidade de suspender a realização de sessões presenciais e procurar distintos formatos de apresentação das obras diante dos impactos da pandemia da Covid-19.
} 
cânone do audiovisual brasileiro, bem como de crescimento do espaço ocupado pelas mulheres no cinema brasileiro, que, como veremos, também se faz sentir na trajetória de outros festivais de cinema de forma ainda mais marcada do que no É Tudo Verdade.

Entre a retrospectiva de 2000 e as mostras do documentário brasileiro dos anos mais recentes do festival, notamos um processo tímido e não linear de releitura e expansão do cânone. Na secção seguinte, voltaremos nosso olhar para relações entre o cânone proposto pelo É Tudo Verdade e as perspectivas desenvolvidas por outros festivais de documentário.

\section{Outros festivais, outros cânones}

Os festivais de filmes têm sido espaços de debate sobre o documentário e sua(s) história(s). Além do É Tudo Verdade vale considerar outros eventos cujas temáticas dialogam com o cinema documental, como Fórumdoc, Recine e Cachoeiradoc.

O Fórumdoc.bh - Festival do Filme Documentário e Etnográfico foi criado em 1997, um ano depois do É Tudo Verdade. Iniciativa da associação Filmes de Quintal, com apoio da Faculdade de Filosofia e Ciências Humanas da Universidade Federal de Minas Gerais, o evento tem tido, desde então, edições anuais na cidade de Belo Horizonte - além de itinerâncias. Inspirado na Mostra do Filme Etnográfico, criada por Patrícia Monte-Mór em 1993, e no Bilan Annuel du Film Ethnographique, criado por Jean Rouch, em 1982, a trajetória do Fórumdoc se marca pela relação do documentário com a antropologia. De acordo com o texto de apresentação do catálogo de 1997, a linha curatorial do Fórumdoc desconfia da "separação absoluta" entre real e ficção, oferecendo uma noção ampliada do cinema documental. Além de debates, cursos e oficinas, o Fórumdoc.bh contou com a publicação de catálogo e, a partir de 2000, com uma seção de ensaios que cresceu em volume de contribuições ao longo dos anos.

A programação do Fórumdoc contou com mostras retrospectivas desde o primeiro ano. De forma semelhante ao É Tudo Verdade, uma parte dessas eram de caráter autoral. Observamos, ainda, filmes/ cineastas em comum nos dois eventos e uma forte presença do cinema brasileiro moderno e contemporâneo, particularmente do Cinema Novo. Notamos, por outro lado, alguns contrapontos, como uma presença maior, no evento mineiro, de secções temáticas, por exemplo 'Imagens da Favela', de 2002, e de obras que se situam fora de uma cinematografia mais canônica ou comercial, por 
exemplo as retrospectivas 'Vídeo nas Aldeias', 8 realizadas nas edições de 1997 e 2004, com exibição de curtas produzidas por cineastas indígenas ou em autoria compartilhada, nas oficinas do projeto. Outras mostras investiram mais diretamente no questionamento das histórias (tradicionais) do cinema, valendo destacar na edição de 2012, 'A mulher e a Câmera', que incluiu, de cineastas brasileiras, A Entrevista (1966) e The Emerging Woman (1975), de Helena Solberg; A Falta que Me Faz (2009), de Marília Rocha; e Luz nas Trevas - A Volta do Bandido da Luz Vermelha (2011), de Helena Ignez. Também em 2012, a mostra 'Cânone e Contra Cânone' trazia filmes de 1950 aos 1980 entre a invenção marginal e o cinema popular, como O Bandido da Luz Vermelha (1968), de Rogério Sganzerla, e Sina do Aventureiro (1958), de José Morica Marins, propondo repensar os cânones do cinema brasileiro moderno:

\begin{abstract}
A narrativa acerca do cinema brasileiro moderno é mais do que conhecida, como conhecidos são seus personagens, momentos cruciais e alinhamentos [...] Mas tanto as cisões internas entre aquelas que seriam as personificações do moderno no cinema brasileiro (cinema novo/ cinema marginal) quanto a aparente oposição entre um cinema que agressivamente se oporia à massificação e aquele que se volta ao grande público vem se revelando - tanto em reavaliações históricas e críticas mais recentes, quanto na retomada mais abrangente e da exibição desse conjunto de filmes - atravessada por um conjunto de personagens e bifurcações que a taxonomia mais habitual da modernidade cinematográfica brasileira não contemplava. (Belico 2012)
\end{abstract}

Outro festival temático que colocou o documentário em pauta foi o Recine Festival Internacional de Cinema de Arquivo, criado no ano de 2002 através de uma parceria do setor de audiovisual do Arquivo Nacional (AN) com a Rio de Cinema Produções. 0 evento, realizado até 2014 na sede do AN, no Rio de Janeiro - quando houve a ruptura entre o arquivo e a produtora -, trazia como temática central o filme de arquivo e os desafios para a preservação da memória audiovisual no país. Tendo como inspiração festivais de cinema de arquivo, como La Giornate del Cinema Muto de Pordenone, organizado pela Cineteca del Friuli e Il Cinema Ritrovato e

\footnotetext{
${ }^{8}$ Criado em 1986, a partir das atividades da ONG Centro de Trabalho Indigenista, sob a coordenação de Vicent Carelli, o projeto 'Vídeo nas Aldeias' promove, por meio de oficinas de produção audiovisual, a formação profissional na área e a realização de filmes em autoria compartilhada com povos indígenas no Brasil. Desde 2000 , o VNA forma uma ONG independente que hoje guarda um acervo audiovisual de mais de 70 filmes, muitos deles com circulação internacional em festivais.
} 
promovido pela Cineteca di Bologna, a proposta do Recine colocava em diálogo o cinema documentário, o filme de arquivo, a história (do cinema) e a preservação audiovisual. Observamos no Recine uma presença marcante do documentário na programação, mas em diálogo com outros formatos, explorando as conexões entre o cinema documental e de arquivo nas últimas décadas. Vale notar, além das mostras competitivas, a realização de mostras informativas cuja curadoria seguia o tema de cada edição do evento. Assim como no É Tudo Verdade e no Fórumdoc, estão presentes no Recine homenagens e mostras dedicadas à obra de um cineasta específico. Destacamos a presença de filmes das primeiras décadas do cinema brasileiro, como na edição de 2011, sobre a Itália, que incluiu uma homenagem a Gilberto Rossi, operador de câmera do período do cinema mudo brasileiro.

Outros festivais de documentários foram criados nos anos 2010. É o caso do CachoeiraDoc, realizado na cidade de Cachoeira, sob organização da professora Amaranta César e do Grupo de Pesquisas e Práticas do Documentário da Universidade Federal do Recôncavo da Bahia. Inspirado no Forumdoc, o festival mobiliza uma definição do documentário como "terreno expandido", como argumenta a curadora em entrevista para o site Cine Festivais (César 2017). O CachoeiraDoc incluiu, desde sua primeira edição em 2010, mostras não competitivas. Além de homenagens a cineastas, essas secções tiveram edições temáticas voltadas para o debate de um cinema político e a inclusão dos novos sujeitos históricos e sociais, como mulheres, negros e indígenas. Ainda na primeira edição, comentando a seleção de Atrás da Porta (2010), de Vladimir Seixas, realizado com o movimento sem-teto no Rio de Janeiro e vencedor do prêmio do júri jovem, Amaranta César (2017) apontava para um perfil do evento como janela para um cinema militante.

Nas mostras especiais e retrospectivas também notamos a presença de filmes que deslocam ou expandem o perfil autoral/ independente, como as obras do projeto 'Vídeo nas Aldeias', homenageadas na terceira edição do festival. Também celebrados pelo Fórumdoc, essas obras não mereceram a mesma atenção no É Tudo Verdade, que apesar de ter exibido filmes de Carelli como Corumbiara (2009), não dedicou mostras especiais ao conjunto de trabalhos do 'Vídeo nas Aldeias'. Observamos outras diferenças, principalmente nos modos de selecionar e organizar as obras, como na edição de 2016 com a mostra 'Com Mulheres', que apresentou um conjunto de filmes realizados por/ com/ sobre mulheres em diferentes programas cuja curadoria foi também realizada por mulheres, como 'Por um cinema 
negro no feminino', assinado por Janaína Oliveira, que exibiu, entre outros, o curta Kbela (2015) da jovem cineasta Yasmin Thayná.

Assumindo o lugar periférico do festival como ponto de partida, Amaranta César (2018) comenta como, em Cachoeira, "foi possível desafiar os sistemas de exclusão cinematográfica e questionar a história contemporânea do cinema brasileiro", ela própria "escrita em espaços críticos hegemônicos" que acabam por reproduzir as "imensas desigualdades da sociedade brasileira". As discussões sobre gênero e a defesa de um cinema político assumem, assim, uma importância no festival, como fica claro na "curadoria provisória" deste ano, em que o racismo, a crise política e a violência da sociedade brasileira atravessam as narrativas dos nove filmes de jovens realizadores escolhidos entre 720 inscritos (Gonçalves 2020, 248).9

Em linhas gerais, notamos nos festivais de filme documentário citados nessa secção uma aposta no documentário como campo de invenção; mas enquanto o É Tudo Verdade apostou na relação com o universo do cinema documentário, o Forumdoc, o Recine e o CachoeiraDoc exploraram as fronteiras e fricções com o filme etnográfico e/ ou de arquivo e o cinema militante, buscando uma definição expandida desse regime cinematográfico.

\section{Conclusão}

Como foi possível notar ao longo do artigo, analisar as relações entre os festivais audiovisuais e a história do cinema nos coloca diante de um desafio. São múltiplas as teias tecidas entre os festivais de cinema cujas temáticas abordam o documentário e as histórias do cinema brasileiro nas últimas décadas. É preciso reconhecer o papel desses eventos como espaços de debate e, também, de publicação e lançamento de obras de cunho histórico, destacando a parceria entre os eventos e as universidades. Através dos anos e das suas várias edições, os festivais de filme documentais têm sido agentes reprodutores de perspectivas historiográficas estabelecidas, mas também espaços de acolhimento de

\footnotetext{
9 Foram eles: À Beira do Planeta Mainha Soprou a Gente (2020), de Bruna Barros e Bruna Castro; Rebu - A Egolombra de uma Sapatão Quase Arrependida (2019), de Mayara Santana Pernambuco; Fartura (2019), de Yasmin Thayná; Thinya (2019), de Lia Letícia; Relatos Tecnopobres (2019), de João Batista Silva; Tipóia (2018), de Paulo Silver; New York, Just Another City (2019), de André Lopes e Joana Brandão; Teko Haxy - Ser Imperfeita (2019), de Patrícia Ferreira Pará Yxapy e Sophia Pinheiro; e Trindade (2020), de Rodrigo R. Meireles.
} 
discursos mais críticos das narrativas tradicionais sobre o cinema brasileiro, valendo notar diferenças substantivas entre as histórias do documentário mobilizadas por esses eventos.

Ao longo do presente texto, buscamos levantar algumas questões sobre a história do cinema proposta pelo festival É Tudo Verdade, com a construção de um cânone em que se destaca o reconhecimento do documentário como um campo de invenção e o privilégio do cinema de autor, reiterando um discurso historiográfico que valoriza o cinema brasileiro dos anos 1950 e 1960. Observamos, por outro lado, movimentos de questionamento e expansão do cânone, ainda tímidos se comparados a outros eventos como o Forumdoc, o Recine e o CacheiraDoc, como na mostra dedicada a B. J. Duarte e nas homenagens a cineastas mulheres que lançaram luz sobre obras menos (re)conhecidas do documentário nacional. Em alguns casos, como na retrospectiva brasileira 'Cinema na TV', de 2002, a realização da mostra apresentava novas possibilidades de circulação para obras cujo acesso ao público encontrava-se limitado ou até mesmo interditado pelas condições de preservação e exibição.

Nos últimos anos, uma série de pesquisas se voltaram para os circuitos sociais dos filmes, estudando a distribuição, a exibição, a recepção e a preservação, entre outros elementos do complexo campo cinematográfico. Os trabalhos sobre os festivais de filmes, em que o presente artigo se inclui, são parte desse processo que busca repensar a historiografia do cinema brasileiro para além das histórias sobre produção e autoria. Conforme argumenta Julian Stringer (2013, 135), o estudo dos festivais como fenômeno histórico mostrou a importância desses eventos na definição de "quais filmes são distribuídos em distintas arenas culturais". Para o autor, a ênfase das histórias clássicas do cinema na produção de filmes escondia a importância dos processos de visibilidade e circulação das obras para a própria construção do cânone. Também Aida Vallejo defende que a recente atenção aos festivais de filmes como objeto de estudo atua no sentido de "corrigir os excessos cometidos na primeira etapa de estudo do cinema como disciplina" (2014, 14, minha tradução), recolocando a distribuição na história do cinema e reconhecendo o papel dos festivais na cultura cinematográfica. Nesse sentido, as pesquisas sobre festivais de filmes podem representar uma chave importante para reler a história do cinema brasileiro, e especialmente, do documentário. 


\section{Referências}

Belico, Ewerton. 2012. "Cânone e Contra-Cânone: Para Aquém da Marginalidade e do Compromisso". In Catálogo Fórumdoc.bh - 16o Festival do Filme Documentário e Etnográfico, editado por Glaura Cardoso Vale, 27-30. Belo Horizonte: Associação Filmes de Quintal.

Bernardet, Jean-Claude. 2008. Historiografia Clássica do Cinema Brasileiro. São Paulo: Annablume.

1979. Cinema Brasileiro: Propostas para uma História. Rio de Janeiro: Paz e Terra.

Carvalho, Vladimir. 2015. Jornal de Cinema. São Paulo: É Tudo Verdade Festival Internacional de Documentários/ Imprensa Oficial.

Cesar, Amaranta. 2018. "De Cachoeira à Paris: Festivals Engagés". Autres Brésils. Acesso em 6 de dezembro de 2020. https://www.autresbresils.net/De-Cachoeiraa-Paris-festivalsengages

2017. “Os Festivais Ainda Olham Pouco para a Produção dos Novos Sujeitos Históricos: Entrevista concedida a Adriano Garrett". Cine Festivais. Aceso em 6 de dezembro de 2020. https://cinefestivais.com.br/os-festivais-ainda-olham-pouco-paraa-producao-dos-novos-sujeitos-historicos/

Da-Rin, Sílvio. 2004. Espelho Partido: Tradição e Transformação do Documentário. Rio de Janeiro: Azougue Editorial.

De Valck, Marijke. 2007. Film Festivals: From European Geopolitics to Global Cinephilia. Amsterdam: Amsterdam University Press.

Di Chiara, Francesco; Re, Valentina. 2011. "Film Festival/ Film History: The impact of film festivals on cinema historiography. Il Cinema Ritrovato and beyond." Cinèmas: Journal of Film Studies 21 (2-3): 131-151.

Formaggini, Beth. 2002. "Texto de Apresentação da Retrospectiva Cinema na TV - Globo Shell Especial e Globo Repórter (1971-1979)”. In Catálogo É Tudo Verdade 2002 - 7o Festival Internacional de Documentários, editado por Paulo Bocatto, 92-104. São Paulo: É Tudo Verdade - Festival Internacional de Documentários.

Freitas, Luciana de Paula. 2020. “Mirada Común a las Visiones Plurales: Los Festivales de Cine Indígena en Brasil”. Diálogo 23 (1): 21-29.

Galvão, Maria Rita. 1975. Crônica do Cinema Paulistano. São Paulo: Ática. 
Gomes, Paulo Emílio Salles. 1980. Cinema: Uma Trajetória no Subdesenvolvimento. Rio de Janeiro: Paz e Terra.

Gonçalves, Beatriz Rodovalho. 2020. "Festival da Libertação Tecnopobre: sobre CachoeiraDoc”. Aniki 7 (2): 245-252.

Labaki, Amir. 2000. "Texto de Apresentação da Retrospectiva Dez vezes Brasil". É Tudo Verdade 2000 - 5o Festival Internacional de Documentários. Acesso em 6 de dezembro de 2020. http://bdetudoverdade.tempsite.ws/2000/iat2000_retrobrasil.htm . 2005. É Tudo Verdade: Reflexões sobre a Cultura do Documentário. São Paulo: Francis Editora.

. 2006. Introdução ao Documentário Brasileiro. São Paulo: Francis.

. 2010. É Tudo Cinema: 15 Anos de É Tudo Verdade. São Paulo: Imprensa Oficial do Estado de São Paulo.

. 2015. A Verdade de Cada Um. São Paulo: Cosac \& Naify.

Lins, Consuelo. 2004. O Documentário de Eduardo Coutinho: Televisão, Cinema e Vídeo. Rio de Janeiro: Zahar.

Lins, Consuelo e Mesquita, Cláudia. 2008. Filmar o Real: Sobre o Documentário Brasileiro Contemporâneo. Rio de Janeiro: Zahar.

Nagib, Lúcia. 2002. O Cinema da Retomada: Depoimentos de 90 Cineastas dos Anos 90. São Paulo: Editora 34.

Mager, Juliana Muylaert. 2019. "É Tudo Verdade? Cinema, Memória e Usos Públicos da História". Tese de Doutorado. Programa de PósGraduação em História, Universidade Federal Fluminense.

Maia, Kamyla Faria. 2015. "Festival enquanto Festa e Dispositivo nos Processos de Visibilidade do Cinema Documentário Brasileiro Pósretomada: o Estudo de Caso do É Tudo Verdade". Dissertação de Mestrado. Programa de Pós-Graduação em História, Universidade Federal de Goiás.

Mattos, Maria Teresa. 2018. "O Festival do Rio e as Configurações da Cidade do Rio de Janeiro". Tese de Doutorado. Programação de PósGraduação em Comunicação, Universidade Estadual do Rio de Janeiro.

Melo, Izabel de Fátima Cruz. 2018. "Cinema, Circuitos Culturais e Espaços Formativos: Sociabilidades e Ambiência na Bahia (1968-1978)”. Tese de Doutorado. Programação de Pós-Graduação em Meios e Processos Audiovisuais, Universidade de São Paulo. 
Morettin, Eduardo. 2005. "Dimensões Históricas do Documentário Brasileiro no Período Silencioso." Revista Brasileira de História 25 (49): 125-152.

Mourão, Maria Dora e Labaki, Amir. 2005. O Cinema do Real. São Paulo: Cosac \& Naify.

Pires, Bianca Salles. 2019. “A Formação de Públicos Cinéfilos: Circuitos Paralelos, Museus e Festivais Internacionais". Tese de Doutorado. Programa de Pós-Graduação em Sociologia e Antropologia, Universidade Federal do Rio de Janeiro.

Ramos, Fernão e Miranda, Luiz Felipe. 2000. Enciclopédia do Cinema Brasileiro. São Paulo: Senac.

Schvarzman, Sheila. 2004. Humberto Mauro e as Imagens do Brasil. São Paulo: UNESP Editora. . 2007. "História e Historiografia do Cinema Brasileiro: Objetos do Historiador". Cadernos de Ciências Humanas 10 (17): 15-40.

Simonard, Pedro. 2006. A Geração do Cinema Novo. Rio de Janeiro: Mauad.

Souza, Ignácio de Melo. 2003. O Estado Contra os Meios de Comunicação (1889-1945). Rio de Janeiro: Annablume.

Stringer, Julian. 2013. "Regarding Film Festivals: Introduction.” In The Film Festivals Reader, edited by Dina Iordanova, 59-68. St. Andrews: St Andrews Film Studies Publishing House.

Tavares, Mariana. 2014. Helena Solberg: Do Cinema Novo ao Documentário Contemporâneo. São Paulo: É Tudo Verdade. Festival Internacional de Documentários/Imprensa Oficial.

Teixeira, Francisco Elinaldo. 2003. Documentário no Brasil: Tradição e Transformação. São Paulo: Summus Editorial.

Vallejo, Aida. 2014. "Festivales Cinematográficos. En el Punto de Mira de la Historiografía Fílmica." Secuencias - Revista de Historia del Cine 39 (1): 11-42.

. 2018. "Festivales de Cine Documental en Iberoamérica: Una Cartografía Histórica. Cine Documental 18: 144-171.

\section{Filmografia}

A Falta que me Faz [longa-metragem, documentário] Dir. Marília Rocha. Teia, Brasil, 2009. 85 mins. 
Aruanda [curta-metragem, documentário] Dir. Linduarte Noronha. INCE, Brasil, 1960. 20 mins.

As Aventuras de Helena [curta-metragem, documentário] Dir. Betse de Paula. Canal Brasil/É Tudo Verdade, Brasil, 2009-2014. 27 mins.

Atrás da Porta [curta-metragem, documentário] Dir. Vladimir Seixas. Couro de Rato/Gume Filmes, Brasil, 2010. 92 mins.

Cabra Marcado para Morrer [longa-metragem, documentário] Dir. Eduardo Coutinho. Mapa produções, Brasil, 1984. 119 mins.

Carmen Miranda - Bananas is My Business [longa-metragem, documentário] Dir. Helena Solberg. RioFilme/Internacional Cinema Corporation/The Corporation for Public Broadcasting; Channel 4 Television et al., Brasil, 1995. 91 mins.

Central do Brasil [longa-metragem, ficção] Dir. Walter Salles. Videofilmes, Brasil, 1998. 113 mins.

Corumbiara [longa-metragem, documentário] Dir. Vincent Carelli. Vídeo nas Aldeias, Brasil, 2009. 120 mins.

Di [curta-metragem, documentário] Dir. Glauber Rocha. Embrafilme, Brasil, 1977. 17 mins.

A Entrevista [curta-metragem, documentário] Dir. Helena Solberg. Produção de Helena Solberg. Brasil, 1966, 19 mins.

Garrincha, Alegria do Povo [longa-metragem, documentário] Dir. Joaquim Pedro de Andrade. Produções Cinematográficas Luiz Carlos Barreto, Brasil, 1963. 61 mins.

Ilha das Flores [curta-metragem, documentário] Dir. Jorge Furtado. Casa de Cinema de Porto Alegre, Brasil, 1989. 13 mins.

Imagens do Inconsciente I [longa-metragem, documentário, filme em episódios] Dir. Leon Hirszman. Leon Hirzsman Produções/Embrafilme/Fundação Roberto Marinho, Brasil, 19831986. 80 mins.

Jango [longa-metragem, documentário] Dir. Silvio Tendler. Caliban Produções Cinematográficas, Brasil, 1984. 117 mins.

Kbela [curta-metragem, documentário]. Dir. Yasmin Thayná. Erika Candido/Monique Rocco, Brasil, 2015. 21 mins.

Luz nas trevas - A Volta do Bandido da Luz Vermelha [longa-metragem, ficção] Dir. Helena Ignez. Mercúrio Produções, Brasil, 2011. 83 mins. 
Mato Eles? [média-metragem, documentário]. Dir. Sergio Bianchi. Sérgio Bianchi Produções Cinematográficas. Brasil, 1983. 33 mins.

O Bandido da Luz Vermelha [longa-metragem, ficção] Dir. Rogério Sganzerla. Filmes Urânio, Brasil, 1968. 92 mins.

O país de São Saruê [longa-metragem, documentário] Dir. Vladimir Carvalho. João Ramiro Mello Produções Cinematográficas, Brasil, $1971.90 \mathrm{~min}$.

Sina do Aventureiro [longa-metragem, ficção] Dir. José Morica Marins. Cinematográfica Apolo, Brasil, 1958. 88 mins.

Socorro Nobre [curta-metragem, documentário] Dir. Walter Salles. Videofilmes, Brasil, 1995. 23 mins.

The Emerging Woman [média-metragem, documentário] Dir. Helena Solberg. Women's Film Project, EUA, 1975. 40 mins.

Viramundo [média-metragem, documentário] Dir. Geraldo Sarno. Thomaz Farkas, Brasil, 1965, 40mins.

\title{
The Contribution of It's All True Film Festival to the Brazilian Documentary Canon
}

\begin{abstract}
The present article is part of a set of studies responsible for rethinking the role of film festivals within film culture. Our analysis focuses on It's All True - International Documentary Film Festival, discussing the type of cinematographic canon presented by the event. We direct special attention to the Brazilian documentary retrospectives and to the festival's publications, while also attempting to promote a dialogue between It's All True's perspectives and different views on the canon elaborated by other Brazilian documentary festivals. We hope, thereby, to offer a preliminary contribution towards a debate on audiovisual festivals and Brazilian film history.
\end{abstract}

KEYWORDS Film festivals; documentary; canon; Brazilian cinema; It's All True International Documentary Film Festival.

Recebido a 10-07-2020. Aceite para publicação a 21-12-2020.

anikiDossier temático: Festivais de Cinema | Special section: Film Festivals 